\title{
Pathogenesis of Inflammatory Bowel Disease: Basic Science in the Light of Real-World Epidemiology
}

\author{
${\text { Davide Giuseppe Ribaldone }{ }^{1, *} \mathbb{C} \text {, Rinaldo Pellicano }}^{2}$ and Giovanni C. Actis $^{3}$ \\ 1 Department of Medical Science, Turin University, 10126 Turin, Italy \\ 2 Department of General and Specialist Medicine, Molinette Medical Center, 10126 Turin, Italy; \\ rinaldo_pellican@hotmail.com \\ 3 The Medical Center and Turin General Hospitals, 10100 Turin, Italy; actis_g@libero.it \\ * Correspondence: davrib_1998@yahoo.com; Tel.: +39-011-6333918
}

Received: 26 August 2018; Accepted: 7 November 2018; Published: 12 November 2018

\begin{abstract}
Major advances in the last few decades have favored the view of inflammatory bowel disease (IBD) as a disease of hyper- or, more often, paradoxical hyporesponsiveness of the gut-associated immune system. The relevant pivot seems to be the loss of the balance between gut-associated pro-inflammatory lymphocytes and the indwelling microbiome species, with inner regulatory circuits (regulatory T-lymphocytes, T-reg) and outer factors (such as drugs, tobacco, diet components) contributing to complicate the matter. Light might be shed by the observation of the real-world IBD epidemiology, which may help unveil the factors that tend to cluster IBD cases to certain geographical areas. A transitional mind frame between bench and real-world gastroenterology could hopefully contribute to restrain the mounting epidemic of IBD in the Western world and to halt the more recent increases seen in many Eastern countries.
\end{abstract}

Keywords: pathogenesis; inflammatory bowel disease; epidemiology

\section{Introduction}

The (inflammatory) disorders of the alimentary tract have accompanied and conditioned modern mankind's history since the 19th century. In this history, inflammation is the keyword, insofar as our alimentary conduit can transform the simple routine action of feeding into a process of sampling of the outer world, and then turn the relevant information back to the inner immune system. The disciplines of medicine, nutrition, behavioral sciences, sociology are all relevant in the study of inflammatory bowel disease (IBD). We shall henceforth attempt to implement these basic notions with the real-life positioning of IBD in the human disease spectrum (epidemiology) and test whether this viewpoint can add to our knowledge of the IBD entity.

\section{Overall Background}

\subsection{Brief History}

Ulcerative colitis (UC) was the first IBD to be described. Relevant symptoms were named by the ancient Greeks [1]; a characterization of the underlying inflammatory process dates back to the early 1800s [2]. The term "ulcerative colitis" was introduced by Sir Samuel Wilks in 1859 [3]. The first complete definition of Crohn's disease (CD) is due to Giovanni Battista Morgagni in 1769 [4], and its recognition as different from intestinal tuberculosis is classically attributed to Crohn, Ginzburg, and Oppenheimer (Mount Sinai Hospital, New York 1932) [5]. The separation between colonic CD and UC was more complex and not very clear until the keystone papers of Lockhart-Mummery and Morson were published in the sixties [6,7]. 


\subsection{Essential Macroscopic Structures}

Understanding the gut wall structure cannot ignore the three primary gut functions. Immune surveillance and nutrient absorption rank first and second in the list (and are functionally intertwined, as reiterated below many times); the aboral movement of luminal contents is the third key function. These tasks condition the functional existence of two layers: the mucosa and the muscularis propria; these two layers are then connected by a third layer, the submucosa, with its peculiar blood vessels and lymphatic collectors [8].

In a functional key of interpretation, which is the declared refrain of this presentation, immune surveillance is the life-saving function and is exerted in an on-off fashion or alternate pro- and anti-inflammatory bouts. The steady state of the system may pivot on the tight separation between the mucosal layer and the overreactive lymphoid tissue underneath. The balance may tip towards inflammation if the permeability is increased, as a result, for example, of tight-junction damage inciting a pro-inflammatory bout. In contrast, this response can be contra-regulated by the death of inflammatory lymphocytes (apoptosis, see below), which may either occur spontaneously or be drug-induced. As expanded on below, the microbiome is the primary source of inciting antigens in this scenario [9].

The effector lymphocytes may undergo several cycles of sensitization and replication in the environment of the Peyer's patches. These are mucosal lymphoid structures thought to direct both immunogenesis and tolerance. The keys of these reactions are the M-cells. With their thin, attenuated membrane, they lie on top of the Peyer's patch and continuously "sample" the lumen content. Antigens or microorganisms eventually trespassing the M-cell to reach the patch germinal center may act as "primers" for the lymphocyte progenies. Such primed cells may ultimately migrate to mesenteric lymph nodes, then reaching the circulation carrying their message of antigen-specific response [10].

This balance implies that the human alimentary tract makes a continuum with the outer world at least in the obvious terms of food introduction and processing; this event in turn is governed by controlled inflammation. The effectors of these events deserve now a closer consideration.

\section{Sub-Cellular and Cellular Effectors}

\subsection{Epithelial Cells}

The intestinal epithelium covers the whole inner surface of the gastrointestinal tract, which may have a surface area of up to $32 \mathrm{~m}^{2}$ in humans [11] and undergoes renewal every $4-5$ days in the small intestine [12].

The intestinal epithelium controls the interactions between microbial flora, environmental factors, genetic factors, and the host immune response in health and disease (such as IBD). Disruption of the tight or the adherent junctions can cause intestinal inflammation [13]. Changes of at least two cell lineages have been linked with the pathogenesis of IBD: (1) goblet cell depletion [14]; (2) homing of a mutated NOD2 intracellular receptor (an IBD risk factor) to Paneth cell progenies that are defective in defensin production [15].

\subsection{The Defensins}

This family of cationic anti-bacterial peptides are released from Paneth cells as alpha-defensins, and from colonocytes as beta-defensins. One study showed a 50\% reduction of expression of alpha-defensin 5 in patients with CD [16]. Contemporary studies concentrating on functional changes of OCTN (organic cation transport) ( $\alpha$-defensins are potential substrates of OCTN1 and 2) found a non-functional mutation hindering the trans-membrane transport of antigenic material in $C D$, anticipating the late demonstration of a defective immune competence in this disorder [17]. Emphasis on mucosal defense mechanisms was reiterated by further studies showing that UC patients may be poor mucus producers, a finding that matches the demonstration of an increased number of epithelia-adherent bacteria in these patients [18]. 


\subsection{Innate Immunity}

Innate immunity is largely based on the sensing of lipopolysaccharide (LPS) on bacterial cell wall, whether speaking of commensals or pathogens. Upon the sensing process, the cytoplasmic Nuclear Factor- $\mathrm{kB}$ (NF- $\mathrm{kB}$ ) signaling complex is unleashed from its inhibitor and allowed to bind the promoter regions of pro-inflammatory cytokine genes, including interleukin (IL)-2. Two specific variants of saccharide sensors are known: the transmembrane Toll-like receptor family (TLR) and the nucleotide oligomerization domain (NOD) subsets [19-21]. Both subspecies signal through the adapter molecule My-D88 and recruit the kinases associated with the IL-1 receptor, before sharing the NF- $\mathrm{KB}$ pathway named above [22]. Loss-of-function mutations on chromosome 16 were interestingly associated with some CD patients in 2001, suggesting an ileal location and a stenosing behavior. Two points of interest were later associated with the mutations of NOD2. Firstly, such mutations were found to be absent from Far East cases [23], and interestingly, though, such variants were consistently found in families affected by the Blau syndrome: children with Blau syndrome typically show arthritis, dermatitis, and uveitis [24]. The consideration of $\mathrm{CD}$ as a disease of immune deficiency was warranted by these observations.

\subsection{Adaptive Immunity}

An abnormal adaptive immunity in IBD is suggested by the fact that:

- Some $70 \%$ of UC patients are pANCA (perinuclear anti-neutrophil cytoplasmic antibody) positive [25].

- Most patients with CD present antibodies to Saccharomyces cerevisiae (ASCA), anti-laminaribioside (ALCA), anti-chitobioside (ACCA), anti-mannobioside (AMCA), anti-laminarin (anti-L), and anti-chitin (anti-C) antibodies, in addition to other antibodies that target microbial antigens, such as anti-outer membrane porin C (anti-OmpC), anti-Cbir1 flagellin, and anti-12 antibody. Also, autoantibodies targeting the exocrine pancreas (PAB) were shown to be highly specific for $\mathrm{CD}$ [26].

- Commensal antigens may be erroneously recognized and presented as foreign to pro-inflammatory Th1 cells (wrong TLRs or wrong antigen-presenting cells may originate these errors) [27]. The issue of the antigen-presenting cells will be again dealt with below.

\subsection{The Microbiome}

This term conventionally indicates a $10^{14}$ microorganism population mainly dwelling within the colon [28]. It is now clear that the quantity and quality of the microbiome species reflect states of health or disease. The microbiome responds to variables that include location, age, drug use, and general lifestyle. The attention of the investigators has recently been attracted by the ability of the microbiome to respond and profoundly change in parallel to socio-economic changes in peace (e.g., feeding habits) or war (e.g., migrations, poverty). Brisk environmental changes may overcome microbiome adaptation rates, possibly igniting the remodeling of gut inflammation (see the conclusive paragraph). The recent phenomenon of massive urbanization in many parts of the world has been associated with observed changes in the microbiota.

\section{Predominant Immune Response Bias in the Gut}

The gut immune system is primarily biased to tolerance. The processes that effect this tolerance environment involve many cells and their mediators.

(a) Most of the gut antibody responses are mediated by immunoglobulin (Ig) subclasses that, incapable to fix complement, can lead to aborted responses [29].

(b) Cell products like mucus and defensins (see above text) can passively avoid close contact between immunogenic luminal contents and the underneath reactive tissues [18-20]. 
(c) The lining epithelium itself constitutes a barrier. Its tight junctions are modulated by zonulin, a 47 KDa protein. Increased zonulin activity can enhance antigens delivery through the paracellular pathway of intestinal epithelial cells, leading to the abrogation of immune tolerance [30].

(d) Many gut processes are terminated via the specific chain of apoptosis, as opposed to regular cell death. For a review of the basic effects involved in apoptosis, see reference [31]. Apoptosis is designed to effect target cell demise while maximally sparing inflammation, a mission that is pursued by targeting single cell groups to reduce to a minimum the release of chemoattractant cell debris. Briefly: (a) The intracellular apoptotic death receptors usually recognize members of the tumor necrosis factor (TNF) family as initiator signals; (b) The execution process is triggered by the caspase cascade, leading to chromatin and organelle disruption; (c) The mitochondria are the final common target: irreversible damage to membranes and permeabilization cause oozing of oxidative compounds promoting cell death.

d.1 Clinical relevance of apoptosis in the setting of IBD Briefly, we wish to reiterate that as many as three of the routinely used drug classes in the control of IBD can be considered apoptosis activators.

d.1.1. Sulfasalazine [32] (but not 5-ASA);

d.1.2. Thiopurines and their metabolites 6-thioguanines can abolish the efficacy of anti-apoptotic factors in lymphocytes via RAC-1 blocking [33];

d.1.3. The anti-TNF monoclonals are caspase inducers and potentially may trigger cell lysis via complement fixation and initiation of antibody-dependent cell-cytotoxicity (ADCC) [34].

(e) The Regulatory T-Lymphocytes (T-Regs)

Since their discovery a few years ago, the lymphocyte population CD4+ CD25+ Foxp3+ has been the target of intense interest. The main reason for this interest rests with the finding that upon specific antigen $(\mathrm{Ag})$ activation, they can exert specific suppressive effects towards the response to the relevant Ag. They could become target of future medical therapy [35]. The finding of the development of autoimmune disorders if T-regs are suppressed and the study of the IPEX syndrome [36] (polyendocrinopathy-enteropathy-X linked) in congenital T-reg malfunction cooperated in boosting trust in the T-regs.

\section{The Trigger Factors of IBD: Genetic Factors, Drug Factors, Leisure Habits, Diet}

\subsection{Genetics (1)—The Case for Monogenic IBDs}

A monogenic IBD may derive from the loss of function of a gene coding for a non-redundant process. The result of the latter events is often an IBD-like pathology that is indistinguishable from genuine IBD [37] but, insofar as aroused by anomaly of a non-redundant yet vital cell function, may prove life-threatening in early childhood. [38]. We have recently [39] compiled a review of these conditions; here, we limit ourselves to an arbitrarily selected presentation.

\subsubsection{X-Linked Apoptosis Inhibitor}

Apoptosis is a crucial cell homeostasis regulator, under the opposing influences of pro- and anti-apoptotic signaling molecules [40]. Overexpression of anti-apoptotic signaling may be at the basis of both some cancers and severe inflammatory disorders. All anti-apoptotic molecules share the ability to bind caspases through baculovirus IAP repeat domains (BIR) [41]. The family of the X-linked inhibitors of apoptosis protein (XIAP) is the most potent and best studied: it effectively neutralizes caspases 3, 7, and 9. XIAP invariably leads to a key triad of clinically severe manifestations: sensitivity to Epstein-Barr virus-induced histiocytosis, recurrent splenomegaly, and IBD [42]. Two pediatric cases of XIAP malfunction have recently been published. Genetic analysis of the first one [43] revealed a 
G to A substitution at a highly conserved position causing a cysteine to tyrosine switch on the XIAP molecule; this child underwent eventual progenitor cell transplant with immediate response. The other case [44] did not undergo bone marrow cell replacement, ran a rocky course, and is now dealing with unchecked fistulizing CD.

\subsubsection{Signal Transduction and Activation of Transcription (STATs)}

STATs are a family of mediators of cell signaling during immune responses, with their intact action depending on the protein family JAK, which can activate specific STATs to downstream signaling [45]. Studies in animal models [46] have shown that loss of STAT function: (a) favors chronic enterocolitis; (b) increases sensitivity to apoptosis, impairs wound healing, increases sensitivity to endotoxin. An intact STAT signaling through IL-10R is necessary to prevent such changes. The consanguineous members of two unrelated families have recently been diagnosed with incurable skin and respiratory infections: documentation of a loss-of-function mutation of IL-10R disclosed the cause of the life-threatening disorder and indicated successful bone marrow replacement [47].

\subsubsection{A Disintegrin and Metalloprotease (ADAM) 17}

ADAM 17 is a disintegrin metalloprotease capable of cleaving TNF, L-selectin, and epidermal growth factor receptor ligands from plasma membranes. When upregulated, ADAM-17 can control cancer and inflammation [48]. The multiplex dysfunctions of three children born to consanguineous parents have recently been described and attributed to failure to activate STAT3 via a normally shed EGF-R (consequence of lacking ADAM-17). The multiple skin, hair, and gut lesions of these subjects responded to treatment and were compatible with a nearly normal life [49]. Incidentally, these findings discourage a strategy of abolishing ADAM-17 to treat inflammatory disease suspected to be due to excess TNF release.

The reader is referred to our review for an exhaustive coverage of this topic [50].

\subsection{Genetics (2)—The IL-23/Th17 Axis as a Significant Pathogenetic Element}

The "IL-23/Th17 axis" is now seen as crucial for the development of IBD [51]. IL-23 is a heterodimeric protein comprising a p19 and a p40 subunit. It is produced by activated macrophages and dendritic cells stimulated by pathogen ligands or pro-inflammatory cytokines, with negative feedback mainly provided by downregulatory cytokines including IL-10.

The lymphocytic IL-23 receptor (R) complex consists of IL-23R and IL12 beta1 that classically contain an extracellular domain, a single transmembrane domain, and a cytoplasmic domain. IL-23 engagement of this IL-23R complex activates at least two members of the JAK-STAT signaling pathway, i.e., JAK-2 and STAT3. The critical function of this IL-23 pathway is mediation of inflammation. This is well illustrated by animal models such as IL23p19 transgenic mice that develop an inflammatory syndrome with lymphocytic accumulations in the small and large intestine accompanied by extra-intestinal infiltrations as well.

The IL23 system is critical for the differentiation and expansion of Th17 cells that produce the IL-17 cytokine which, in turn, by stimulation of the production of inflammatory mediators-IL-1, IL-6, IL-8, TNF, and others-endows Th17 cells with their characteristic functions: microbial defense (which is critical in the polymicrobic colonic environment) and maintenance of chronic inflammation in various non-autoimmune (infectious) or autoimmune conditions. IL-23 is constitutively expressed in the terminal ileum but is induced during inflammation, according to animal models, such as cell transfer and IL-10 knockout mice (reviewed in reference [51]). Of note, myeloid-based STAT3 deficiencies also lead to the development of colitis, anticipated by the knowledge that functions of STAT3 include pro-inflammatory activities and regulatory activities mainly dependent on IL-10.

Another downregulatory cytokine that is potently induced by IL-23 is IL-22, which not only downregulates the degree of IL-23-dependent intestinal inflammation but also promotes epithelial cell restitution at different sites, i.e., intestine and lungs. Thus, the IL-23/Th17 axis both promotes primary 
inflammatory reactions and drive secondary features of contra-suppression and tissue repair, mostly via STAT3 activation.

Genome-wide association (GWA) studies have now identified multiple single nucleotide polymorphisms (SNPs) in the IL-23R gene region as being associated with both CD and UC, with disease-protective and disease-enhancing polymorphisms of IL-23 identified; the data so far point to a role of the IL-23/Th17 axis common to the pathogenesis of the two polar IBD phenotypes, UC and CD. Interestingly, similar SNPs have been identified in inflammatory systemic disorders already described in association with IBD, i.e., psoriasis and ankylosing spondylitis, emphasizing that the basic immunologic circuitry that contributes to IBD is likewise operative "beyond the boundaries of the bowel".

On the other hand, such complex axes are not thoroughly understood. In animal models, IL-17A was shown to be protective against $\mathrm{T}$ cell-mediated colitis: IL-17A-deficient mice showed rapid weight loss and severe colitis. It has been postulated that loss of IL-17A could lead to an imbalance of pro-Th1 inflammatory cytokines, leading to severe colitis. In addition, genetically defective IL-17 immunity in humans was associated with a risk of chronic mucocutaneous candidiasis. Current evidence suggests that inhibition of IL-17 may induce inflammation in the gastrointestinal tract by favoring Th1 pathways and/or changing the mycrobiome composition [52].

Being IBD, spondyloarthritis, and psoriasis tightly associated, probably they are not distinct diseases, but different expression of a common inflammatory process [53].

\subsection{Diet}

The recent increase of the global prevalence of IBD cannot be simply attributed to genetics: while only the monogenic forms can readily be explained on this ground, the bulk of the sporadic IBDs call other factors into question. Among the environmental factors, diet arouses much interest. High intake of fruits and vegetables seems to reduce the likelihood of manifesting IBD; by contrast, refined cereals, alcohol, salt, certain oils, fructose derived from corn, fatty meat, and processed foods in Western regions, all seem to promote inflammatory processes [54]. Both lay magazines and the scientific literature have synergized in the past years to indicate the so-called "Western diet" as the culprit for the sufferings of modern society. According to a loose definition, "Western diet" is a feeding style that is rich in saturated fats, red meat, and carbohydrates and low in fresh fruits, vegetables, whole grains. In the majority's opinion, none of the individual components of a Western diet can be blamed for being pathogenic; rather, the prolonged use of such a feeding style seems to favor loss of microbiome diversity and propensity to autoimmune disease, including CD. By contrast, people on an agrarian diet including raw plant and fiber-based foods were less prone to clinical dysimmunity [55].

While the contribution of the diet to the onset of IBD is generally recognized, the influence of food on the course of the disease is not clear [56]. Special nutritional schemes worked out by pediatric gastroenterologists play a role in inducing remission in children [57]. Because malnutrition is frequent, its assessment and nutritional supportive care are important aspects of multidisciplinary patient management [58]. Apart from yogurt, patients with IBD tend to avoid dairy products fearing an exacerbation of their symptoms. Nevertheless, there is no convincing evidence that milk and its derivatives act as triggers for disease recurrence [59].

Diet Could Have Effects Beyond the Bowel

At a close scrutiny, the simple act of feeding implies a dialogue between an extraneous antigenic load and the lymphoid gut structures, with inflammation playing the arbiter of any imbalance. Indeed, excess feeding, overweight, and serum inflammatory markers are easily found in American lower-class children [60]; further intriguing and worrisome, is the consistent finding of an intellectual decline in these premises [61], as we describe below.

Dror et al. [62] published a study regarding the possible link between incorrect diet and intellectual decline. If the complex of these changes was known to accompany obviously pathologic alimentation, 
the team of Dror has recently described the changes attached to routine feeding [62]. Their research was based on two basic demonstrations. Firstly, pancreatic B cells producing insulin abundantly display receptors for IL-1 $\beta$ (the chief pro-inflammatory cytokine): insulin secretion may be an immune-inflammatory event. Secondly, routine feeding from the immunologic point of view is a barely tolerated process, with a peritoneal macrophage reaction being raised in response to bacterial products (LPS) leaking from the intestinal wall. Thus, in this scenario, activation of Langerhans cells and insulin release upon feeding are promoted by the two events of blood glucose elevation and IL-1 beta release from primed macrophages; the crucial side effect is the upgrading of inflammation in the system [63]. Notably, in this chain of events, glucose can preferentially be captured by activated immune cells displaying the GLUT-1 receptor (this receptor class allows glucose uptake in the absence of insulin). The competition for glucose between immune cells and neural tissues might have caused human brain shrinking in archaic eras; nowadays, it may be the explanation for the intellectual decline described in some epidemiologic studies [64].

These findings might underscore the gut inflammogenic potential.

\subsection{Induction by Drugs}

Drug-induced IBD can be triggered or exacerbated by non-steroidal anti-inflammatory or other drugs that interfere with anti-inflammatory prostaglandins [65]. However, the study of drug-induced IBD has recently focused on anti-TNF agents. Most interestingly, a review of the unwanted effects of the formulations used in the last decade for a variety of immune-mediated diseases, including, particularly, rheumatoid arthritis (RA) and IBD itself, has revealed that such drugs can unpredictably induce a paradoxical IBD, together with cases of psoriasis and uveitis [66].

Etanercept is a fusion protein that blocks the TNF receptor without inducing lymphocyte apoptosis and is the drug most frequently implicated in this immunologic toxicity [66]. Its ineffectiveness in the treatment of IBD, but not in rheumatoid disorders compared to other anti-TNF drugs like infliximab and adalimumab, is probably due to distinct disease processes and different mechanisms of action of the drugs. Both infliximab and etanercept neutralize TNF-alpha, but infliximab complexes are more stable with membrane-bound TNF than etanercept. However, only infliximab can bind to peripheral blood lymphocytes and lamina propria $\mathrm{T}$ cells and induce apoptosis of activated lymphocytes. Infliximab can lyse TNF-producing cells by complement activation, but etanercept cannot. The use of etanercept in ankylosing spondylitis patients is associated with an increase in interferon- $\gamma$-positive and TNF- $\alpha$-positive CD4+ T cells and CD8+ T cells. An increase in the production of these cytokines in genetically predisposed patients may induce IBD [67].

A recent study has shown that TNF inhibitors can increase the expression of the $\alpha-4 / \beta-7$ integrin in CD4+ lymphocytes, so boosting the gut-seeking potential of the pro-inflammatory cells that happen to be present in these populations [68]: thus, such findings can provide a clue to the understanding of the paradoxical autoimmune effects of TNF- $\alpha$ blockers. In clinical practice, we encountered a 22-year-old male who, treated with etanercept for juvenile RA, developed histologically evident UC unresponsive to azathioprine and also to adalimumab and infliximab [69]; this patient is currently been considered for bone marrow transplant. Again, these data suggest that common mechanisms underlie the pathogenesis of numerous immune dysfunction phenotypes including IBD.

\subsection{Leisure Habits: Smoking}

The effects of tobacco on IBD have long eluded investigators' efforts: patients with CD who continue to smoke were classically known to worsen or need more drugs to maintain remission, whereas those with UC had long learnt that "lighting up" would prove protective, with frequent drug sparing. Even more intriguing and clinically meaningful, patients with UC (but not those with $\mathrm{CD}$ ) who smoke are known to often experience a severe disease flare, occurring months or even years after quitting cigarettes [70]. A satisfactory answer to this confusing evidence came from the results of experiments wherein animals underwent an LPS-driven septic shock [71]. Briefly, it was 
shown that the expansion of this response could be controlled by a resected vagal fiber; furthermore, the mediator of this vagal protective action was acetylcholine (Ach). Specifically, Ach was found to bind the macrophagic nicotinic receptor $\alpha-7-n A c h R$, blunting the subsequent release of inflammatory cytokines [72]. At this point, it is easy to envisage that tobacco can restrain UC through the binding of the same nicotinic receptor, and, similarly, that disease rebound can be expected following tobacco quitting and clearance from Ach of the binding site on inflammatory macrophages. Experiments of vagal nerve stimulation to treat various phases of IBD are currently under way [73].

\section{The Kick-Out Factors in IBD: Antigen-Presenting (Dendritic) Cells}

Proper antigen presentation to pro-inflammatory lymphocytes by dendritic cells is vital for an efficient yet regulated reaction: an excessively short half-life of the antigen-presenting cells (APCs) would leave lymphocytes short of the inciting antigen, but an excessive APCs persistence can obviously lead to detrimental inflammation [74]. This might happen in some IBD cases, wherein failure of APCs to die out (apoptosis resistance) may not only cause uncontrolled immunity but also cause failure to recruit T-reg cells (see also the above text), insofar as T-regs depend on a correct function of APCs [75]. APCs may commonly become resistant in protracted IBD inflammation, if they become replaced by the so-called non-professional APCs [76].

\section{IBDs in Real Life: Clues from Epidemiology}

The preceding paragraphs, containing a robust deal of basic science, have confirmed a core of rather classic concepts on IBDs, as follows. IBDs are multifactorial syndromes pivoting on the phenomenon of inflammation. Though presenting as a response to the outer environment, inflammation is also sustained by inner immunologic variants, which, beyond other features, impart to IBD the behavior of a low-penetrance genetic defect. Analysis of the way specific disease cases cluster together can shed light on their etiology and pathogenesis; on the basis of this tenet, we decided to conclude this tentative review with an emphasis on the epidemiology of IBD.

\subsection{World Epidemiology}

It is estimated that currently $>3$ million individuals have IBD in Europe, and the global population includes 5 million of patients with IBD. A time-trend analysis has shown that $75 \%$ of CD studies and $60 \%$ of UC studies reported an increasing incidence of statistical significance [77].

\subsection{East Meets West: A Paradigm for the Role of Environmental Factors}

Rapid industrialization and inurbation of wide areas in the East (see below) has coincided with increasing incidence and prevalence of IBD. Recent studies have reported an IBD incidence over Asia of 1.37 per 100,000, with figures of 3.4 per 100,000 for China. These figures indicate a trend to rise, if compared with traditional incidence figures of 0.60-3.44 [78]. As early as 2015, the reasons for this escalation were enumerated as: life westernization, use of appendectomy, milk formula feeding, changing diets (to be covered below) [79]. These data are confirmed by a rising incidence of IBD of epidemic proportions in some Iran regions featuring aggressive industrialization [80].

\subsection{Similar Orders of Figures Have Long Been the Matter of Scrutiny with Regard to the Incidence of Pediatric $I B D(C D)$ in the South Island of New Zealand}

Data from a recent study [81] have confirmed an epidemic-like behavior of CD in the area, with one of the highest incidence peaks worldwide. Causative hypotheses, including reduced bioavailability of vitamin D in the area, are fueling an instructive debate. 


\subsection{Clues from Migratory Events}

Relevant information can be obtained from migration studies. In Canada, Eastern families which adopt a Western lifestyle may achieve IBD incidence figures that match those of the other inhabitants; children seem to be maximally sensitive to local injuring factors (detailed below) [82]. Cuban exiles rejoining their families in Florida have been described to achieve a "North American" IBD risk. Interestingly, though, the authors of the survey have observed a progressive decrease of the lag time between arrival to Florida and IBD onset [83]. Responding to the authors' queries, we set forth the hypothesis of a worsening anxiety of the migrants in response to the rapid changes of the social conditions in the USA in the last year, fueling further inquiries [84]. Thus, studies of the IBD dynamics have raised more questions than answers, and it is with genuine anticipation that we reappraised a few recent studies of urbanization of IBD patients emphasizing the role of the microbiome changes.

\section{Urbanization: IBD Epidemiology and Microbiome}

Urbanization makes global changes in these days, and, on a simple frequency basis, cannot avoid affecting a proportion of IBD cases. The crucial observation is that city limits make a kind of a "secluded" environment, where factors are identifiable and, hopefully, easier to classify. On the basis of these premises, a researcher from Lund (Sweden) asked how the urban environment changes organism ecology. Of utmost relevance and luck for our topic, the author chose two measures that characterize IBD: oxidative stress and inflammation [85]. To this end, we like to incidentally emphasize that the recognition of "pro-inflammatory factors" in urbanized areas has already been made by non-gastroenterologists, who have proposed for those exposed to such factors the fantasy label "inflammacitizens" [86]. Noise pollution of city areas may be chronic (public and private transportation) or occasionally acute (concerts, festivals, etc.). Noise can obviously favor anxiety. Relevant to the issue of IBD, we have above stressed a possible link between increased anxiety levels and increasingly aggressive IBD in Cuban exiles migrating to the US [83]. Exuberant light at night is a matter of boast for many Western cities. Unfortunately, experts in feeding behavior and gut diseases may see prolonged night illumination as a chance for unduly prolonged access to food (often street junk food), hence a pro-inflammatory factor [87].

Hereunder, we briefly comment on three of the urban factors that this Swedish investigator has linked to disturbed inflammation and oxidative stress.

\subsection{Chemical Pollution}

Heavy metals, nitrogen oxides, nanoparticles (the well-known PM10 from vehicles' exhaust pipes), and polycyclic hydrocarbons are all pro-inflammatory and can increase reactive oxygen species (ROS) formation $[85,88]$.

\subsection{Infectious Disease}

Unexpectedly, research has shown that city life may be a risk for infectious diseases. The agent might often be a wild animal, which will be variously attracted by the presence of water pools or, most importantly, by the availability of food leftovers by restaurant backdoors [89]. Birds and foxes might be the frequent vehicles, with lower class children most frequently affected. In the US, it is reckoned that most children from low-income families might experience up to five diarrheal episodes before the age of 5 years, a condition that predisposes to chronic mesenteric inflammation favoring CD [90].

\subsection{Lack of Physical Exercise and Microbiome}

Nowadays, it is being emphasized that a diet poor in vegetables makes a poor antidote against inflammation. The presence of processed meat and deep-fried cooking used by many city workers coping with nightshifts can favor the intestinal growth of the Bilephila wadsworthi, a pathogen capable to 
erode intestinal defensins and expose the mucosa to the pro-inflammatory action of further pathogens. We have covered this issue in a recent review [91].

The availability of efficient means of transportation and strict schedules obviously force most citizens to use subways and connecting train services, preventing people from walking. Unfortunately, physical exercise is one efficient means to activate muscles to release their myokines (IL-6, IL-8, IL-15) which in turn will direct the monocytic release of lactoferrin. [92]. To this end, we emphasize that lactoferrin exerts its potent anti-inflammatory effect ever since the newborn phase, where it is secreted in colostrum, through the adult phase, where it contributes to the selection of intestinal Bifidobacteria [93] and terminates inflammation by disrupting the inciting LPS molecules [93]. In other words, muscles are the forgotten immunoregulatory organs involved in the lactoferrin circuitry, and evidence is already sufficient to state that people neglecting physical activity are strong candidates to (dys)immune disease.

At this point, a description of the microbiome changes underlying the facts described above is largely due. A recent review of microbiota and urbanization [94], mastered by a group based in China and Australia, turns out to be of an utmost usefulness. Taking advantage of the peculiar position of their observatory at the opposite side of Europe, the authors are familiar with data from several regions that have recently hosted brisk society changes (including urbanization), with China and its huge population contributing a significant example. The reports from the Asia-Pacific Crohn's Colitis Epidemiology study (ACCESS) compared the incidence of IBD in Australia with that in China, Hong-Kong, Sri Lanka, Indonesia, and other countries: it was found that the highest figures coincided with the most industrialized and inurbated regions [95]. In a meta-analysis of 40 studies [96], the authors examined the pooled incidence ratios of IBD between urbanized and rural regions, finding a significantly higher IBD risk for the urbanized areas. As expected, these data strongly suggested a link between IBD risk and urbanization.

Should one then ask about the microbiome configurations underlying these IBD risk maps, a few tenets might be the key to interpretation: (1) The microbiome composition is highly flexible and adapts to the subject's prevalent alimentation; (2) Thus, microbiome configuration, by and large, might mirror ways of feeding; (3) Loss of given microbiome species because of a supervening lack of substrate can be replaced by exchange of body fluids (chiefly saliva) with other subjects. Paradoxically, in these cases, increased promiscuity should be regarded as a positive value (reviewed in reference [94]).

In general, populations living on agricultural products are rich in the Prevotella and Xylanibacter genera that have the machinery for cellulose and xylan hydrolysis; their urbanized counterparts, by contrast, are rich in Bacteroides, Alistipes, Blautia, Ruminococcus, and Bilophila [97].

Several studies have shown that there is a significant reduction in the diversity of the stool microbiome of individuals with IBD: $25 \%$ fewer genes were detected in the fecal samples of IBD patients than in those of control patients. Dysbiosis is associated with the pathogenesis of IBD, but it is not clear whether this is a cause or a result of the inflammatory process.

The microbiota of patients with IBD is characterized by depletions of bacteria with anti-inflammatory effects, including Bifidobacterium adolescentis, Faecalibacterium prausnitzii, and other butyrate-producing bacteria, such as Dialister invisus, and an expansion of pathogenic bacteria (pathobionts), including Proteobacteria such as adherent-invasive Escherichia coli (AIEC), Ruminococcus gnavus (a mucolytic bacteria), Campylobacter concisus [98].

The number of sulfate-reducing bacteria, such as Desulfovibrio, is higher in IBD patients, resulting in the production of hydrogen sulfate that damages intestinal epithelial cells and induces mucosal inflammation. An increase in ambient oxygen levels induced by hyperemia and increased vascular and mucosal permeability is thought to be one of the mechanisms responsible for the reduction of obligate anaerobes (Clostridium groups IV or XIVa), with expansion of aerobes and facultative anaerobes (Enterobacteriaceae). Figure 1 is intended to highlight a few of the basic concepts enumerated above.

If naturally delivered, a newborn is exposed to the environmental microbiota of maternal origin, an essential station on the road to a healthy growth. The mode of delivery strongly affects the 
composition of the microbiota. In the case of caesarean delivery (C-section), other environmental bacteria form the basis for the microbiota, instead of vaginal and fecal bacteria from the mother, reportedly resulting in a substantial reduction of Bifidobacteria. Other factors influencing microbiota composition are the type of infant feeding, gestational age, infant hospitalization, and antibiotic use by the infant. The microbiota of breast-fed infants is dominated by Bifidobacteria, whereas the counts of E. coli, Clostridium difficile, Bacteroides fragilis, and Lactobacilli are higher in exclusively formula-fed infants. The first microbes colonizing the intestinal tract hold a pivotal role. Once the core microbiota has developed, it stabilizes to become less sensitive to modification. Life events such as diet changes, illnesses, and antibiotic treatments disturbing this settlement process were associated with large shifts in the abundances of major groups in the affected infants [99].

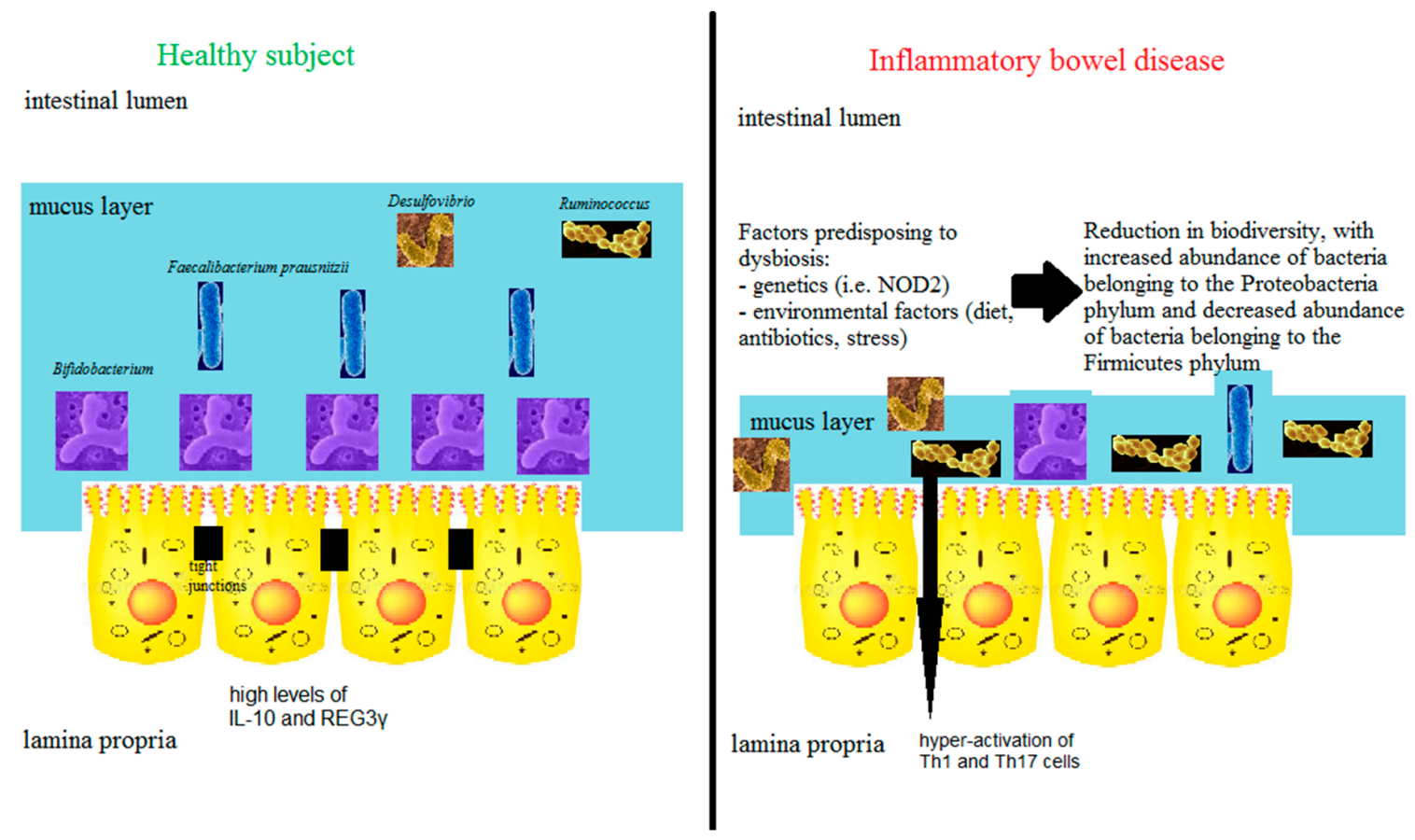

Figure 1. Dysbiosis is an unfavorable composition and function of the gut microbiota. Host-microbiota interactions and host immune system are both disturbed by dysbiosis. The latter, rather than the presence of specific pathogens, is likely to affect the development of inflammatory bowel diseases. Relevant changes may include reduction of anti-inflammatory Phila (Bifidobacteria) and expansion of pathogenic Proteobacteria (Ruminococcus and Desulfovibrio). Barrier integrity and innate and adaptive immunity can all be affected by the changes. Hyperactivation of Th1 and Th17 cells, increase of tight junction permeability, reduction of T-regs, and decrease in REG3gamma and IL-10 are the cell counterpart of these disorders.

Metagenomic sequencing of IBD patients revealed hallmarks of microbiome dysbiosis with a general reduction in the diversity of the microbial community compared to healthy controls (HC). Metagenomics has expanded the ability not only to detect microbial communities but also to provide insight into the functional effects of the microbial composition in IBD. In particular, metagenomics allows the investigation of the distribution of virulence factors across the microbiome, which has not been systematically studied or previously reported in IBD. A greater prevalence of virulence factors from $E$. coli in IBD patients has been observed. Virulence factors from Clostridium perfringens were only present in patients with IBD and undetectable in HC. The most prevalent virulence factors that were identified among the IBD cohort are Enterotoxin (senB) (22\%), Hemoglobin protease (vat) (17\%), Hemolysin A (hlyA) (11\%), Hemolysin B (hlyB) (10\%), Hemolysin C (hlyC) (10\%), Hemolysin D (hlyD) (10\%), Cytotoxic necrotizing factor 1 (cnf1) (10\%), invasion protein IbeA (ibeA) (9\%), Secreted 
autotransporter toxin (sat) (8\%), and Tir domain-containing protein TcpC (tcpC) (8\%). Thus, the expression of virulence factors in a dysbiotic microbiome may contribute to pathogenesis in IBD [100]

Geographical differences are very important, and the selection of controls in the studies is crucial to correctly interpret the results. It is well known that host lifestyle affects gut microbiota; the gut microbiota harbored, for example, by the Chinese population is different from that harbored by the Western population. Despite the overall microbial difference, the results of the differential abundance analyses in a recent study [101] suggest that the microbial shift in Chinese IBD patients, compared to HC subjects, may resemble that in Westerners. These findings suggest that there are consistent changes in the gut microbiota of IBD patients across populations and that these changes can serve as universal biomarkers for the classification of IBD states.

The gastrointestinal microbiota can be divided into two ecosystems: the luminal microbiota in the feces and the mucosal microbiota that is present in the intestinal epithelium. Because of its close proximity, the mucosal microbiota is more likely to be involved in intestinal diseases than its luminal counterpart. Mucus layers, composed of a dense inner mucus part and a loose outer mucus fraction, play an important role in protecting intestinal epithelial cells from the gut microbes and pathogenic microorganisms. Most of the gut microbiota is present in the outer mucus layer. Inflammatory responses lead to a reduction in the number of goblet cells and reduce mucus layer thickness, altering mucus composition. These changes enable easy contact of microbes with epithelial cells, stimulating an inflammatory response. However, owing to the ease of acquisition and ethical considerations, most previous studies examined the fecal microbiota rather than the mucosal-associated counterpart.

These pathologic trends are thought to further worsen in more "educated" societies where sophisticated human relationship or simple prejudice have inadvertently sowed erroneous behaviors. For example: the widespread use (now decreasing) of the cesarean section at birth [102] has deprived millions of children all over the world of the gift to "sign" their microbiome with their mothers' vaginal flora; excessive hygiene has prevented an early education of their immune system; inhibition of free contact with their playmates has hampered the reconstitution of microbiome diversity [103].

Recommendations such as that of encouraging promiscuity and unleash children to play in the dirt may sound absurd to those struggling for the approval of rules that restrain Helicobacter pylori infection (just as an example) but may be welcomed as a rediscovered wisdom by all those who are worried by the yet glittering landscapes of Western cities being invaded by crowds of "inflammacitizens" [86] depressed and debilitated by immune diseases [104].

\section{An Attempt at a Holistic Vision}

The factors previously mentioned as associated with IBD, i.e., the environment, the genes, the microbiota, and the immune system, may all be critically important but, given their individual complexity, they may call for a functionally integrated vision. The concept of an interactome does underlie this endeavor. In its broadest definition, an interactome indicates the whole set of molecular interactions in a given cell. Such interactions may regard antigens (for example proteins) but can also describe sets of indirect interactions among genes [105]. Of course, this brief paragraph is not meant at all to enter the complex matter of interactomes in any depth. For the sake of our IBD topic, we wish to succinctly remark that an interactome may also be intended to identify sets of mechanisms that are indispensable for a disease to be maintained, and, ideally, families of drug molecules capable to target those mechanisms to effect disease termination. Intuitively, such attempts may acquire specific importance in the case of chronic inflammatory disorders, (i.e., IBD), wherein the availability of precisely aimed bullet drugs is eagerly awaited in the face of the unacceptable toxicity often linked to inaccurate target framing as per conventional algorithms.

The construction of the interactome can start with a seed gene selection derived from existing databases, such as genome-wide associated studies; synergy with current literature will be followed by algorithms designed to identify a particular molecular neighborhood of the network that represents the "disease module"; this will then be validated on the basis of gene expression data, gene ontologies, 
other pathways, etc. Such a process should allow to reach a biological interpretation of the disease module, the prioritization of the most important pathway(s), and the identification of the molecular targets that control the whole disease network (the disease interactome). Next, high-throughput discovery screening should match drugs existing in compound databases with the molecular targets identified in the disease interactome [106]. To define the IBD interactome, new concepts and tools are needed to implement the approach: an unbiased data-driven integration strategy that reveals key players of the system, pinpoints the central drivers of inflammation, and enables the development of targeted therapies. Powerful bioinformatics tools able to query and integrate multiple "omes" are available, enabling the integration of genomic, epigenomic, transcriptomic, proteomic, metabolomic, and microbiome information to build a comprehensive molecular map of IBD. As anticipated above, this approach will enable the identification of IBD molecular subtypes, correlations with clinical phenotypes, and elucidation of the central hubs of the IBD interactome that will aid the discovery of compounds that can specifically target the hubs that control the disease [107].

In our (perhaps biased) opinion, inflammation makes one of these IBD hubs: its place in evolution, its functions, and the mode these functions are exerted support this view: (1) Inflammation is one of the most conserved biological processes [91]; (2) Besides its occasional roles of acute defense, it prevalently acts as a lingering arbiter of the immune dialogues at the barrier gut surface [86]; (3) In its peculiar variant classified as "apoptosis", these functions are paradoxically exerted "in the absence of inflammation" [31], a key pathway to tissue integrity.

\section{Conclusive Thoughts}

For years, the inflammatory disorders of the gut have been thought to depend on ill-defined infections or autoimmunity. The discovery and (partial) characterization of the microbiome has impacted these uncertainties: it was shown that the microbiome turns the gut into a sort of "sixth sense" capable to continuously probe the outer world and elicit a remodeling inflammation, which may be the basis of what we named "IBD". This knowledge is now opening the path to behavioral therapeutic approaches, reaching beyond the mechanistic use of traditional immune modulators or surgery.

As the final message from this review, we like to stress that the knowledge accumulated so far permits to move from the concept of IBD as an "accident coming out of the blue" towards the understanding of a "protagonist complex of changes originating from the gut (but not exclusively affecting the gut) that deepens its roots into the socio-economic variables of contemporary societies".

Author Contributions: Concept, researching and writing: G.C.A.; advice, writing and editing: D.G.R and R.P.

Funding: This research received no external funding.

Acknowledgments: This research received no external funding.

Conflicts of Interest: The authors declare no conflict of interest.

\section{References}

1. Lim, M.L.; Wallace, M.R. Infectious diarrhea in history. Infect. Dis. Clin. N. Am. 2004, 18, 261-274. [CrossRef] [PubMed]

2. Francois Joseph Victor Broussais (1772-1838). System of physiological medicine. JAMA 1969, $209,1523$.

3. Wilks, S. Morbid appearances in the intestines of Miss Bankes. Lond. Med. Gaz. 1859, 2, 264-265.

4. Adams, E.W. Founders of modern medicine: Giovanni Battista Morgagni (1682-1771). Med. Libr. Hist. J. 1903, 1, 270-277.

5. Crohn, B.B.; Ginzburg, L.; Oppenheimer, G.D. Regional ileitis: A pathologic and clinical entity. J. Am. Med. Assoc. 1932, 99, 1323-1329. [CrossRef]

6. Lockhart-Mummery, H.E.; Morson, B.C. Crohn's disease (regional enteritis) of the large intestine and its distinction from ulcerative colitis. Gut 1960, 1, 87-105. [CrossRef] [PubMed] 
7. Lockhart-Mummery, H.E.; Morson, B.C. Crohn's disease of the large intestine. Gut 1964, 5, 493-509. [CrossRef] [PubMed]

8. Graham, M.F.; Blomquist, P.; Zederfeldt, B. The alimentary Canal. In Wound Healing: Biochemical and Clinical Aspects; Cohen, I.K., Diegelmann, R.F., Lindblad, W., Eds.; Saunders: Philadelphia, PA, USA, 1991.

9. James, S.P. Mucosal Immune Regulation. In IBD, From Bench to Bedside; Shanahan, F., Targan, S., Eds.; Williams and Wilkins: Baltimore, MD, USA, 1984; pp. 65-77.

10. Strober, W.; Brown, W.R. The mucosal Immune System. In Immunologic Diseases; Samter, M., Talmage, D.W., Frank, M.M., Austen, K.F., Claman, H.N., Eds.; Little and Brown: Boston, MA, USA, 1988; Volume 1, pp. 79-139.

11. Helander, H.F.; Fändriks, L. Surface area of the digestive tract-Revisited. Scand. J. Gastroenterol. 2014, 49, 681-689. [CrossRef] [PubMed]

12. Van der Flier, L.G.; Clevers, H. Stem cells, self-renewal, and differentiation in the intestinal epithelium. Annu. Rev. Physiol. 2009, 71, 241-260. [CrossRef] [PubMed]

13. Okamoto, R.; Watanabe, M. Role of epithelial cells in the pathogenesis and treatment of inflammatory bowel disease. J. Gastroenterol. 2016, 51, 11-21. [CrossRef] [PubMed]

14. Surawicz, C.M.; Haggitt, R.C.; Husseman, M.; McFarland, L.V. Mucosal biopsy diagnosis of colitis: Acute self-limited colitis and idiopathic inflammatory bowel disease. Gastroenterology 1994, 107, 755-763. [CrossRef]

15. Wehkamp, J.; Harder, J.; Weichenthal, M.; Schwab, M.; Schäffeler, E.; Schlee, M.; Herrlinger, K.R.; Stallmach, A.; Noack, F.; Fritz, P.; et al. NOD2 (CARD15) mutations in Crohn's disease are associated with diminished mucosal alpha-defensin expression. Gut 2004, 53, 1658-1664. [CrossRef] [PubMed]

16. Wehkamp, J.; Salzman, N.H.; Porter, E.; Nuding, S.; Weichenthal, M.; Petras, R.E.; Shen, B.; Schaeffeler, E.; Schwab, M.; Linzmeier, R.; et al. Reduced Paneth cells alpha-defensins in ileal CD. Proc. Natl. Acad. Sci. USA 2005, 102, 18129-18134. [CrossRef] [PubMed]

17. Noble, C.L.; Nimmo, E.R.; Drummond, H.; Ho, G.T.; Tenesa, A.; Smith, L.; Anderson, N.; Arnott, I.D.; Satsangi, J. The contribution of OCTN1/2 variants within the IBD5 locus to disease susceptibility and severity in Crohn's. Gastroenterology 2005, 129, 1854-1864. [CrossRef] [PubMed]

18. Swidsinki, A.; Ladhoff, A.; Pernthaler, A.; Swidsinski, S.; Loening-Baucke, V.; Ortner, M.; Weber, J.; Hoffmann, U.; Schreiber, S.; Dietel, M.; et al. Mucosal flora in inflammatory bowel disease. Gastroenterology 2002, 122, 44-54. [CrossRef]

19. Iwasaki, A.; Medzhitov, R. Toll-like receptor control of the adaptive immune responses. Nat. Immunol. 2004, 5, 987-995. [CrossRef] [PubMed]

20. Hugot, J.P.; Chamaillard, M.; Zouali, H.; Lesage, S.; Cézard, J.P.; Belaiche, J.; Almer, S.; Tysk, C.; O'Morain, C.A.; Gassull, M.; et al. Association of NOD-2 leucine rich repeat variants with susceptibility to Crohn's. Nature 2001, 411, 599-603. [CrossRef] [PubMed]

21. Ogura, Y.; Bonen, D.K.; Inohara, N.; Nicolae, D.L.; Chen, F.F.; Ramos, R.; Britton, H.; Moran, T.; Karaliuskas, R.; Duerr, R.H.; et al. A frameshift mutation in NOD2 associated with susceptibility to Crohn's disease. Nature 2001, 411, 603-606. [CrossRef] [PubMed]

22. Strober, W.; Murray, P.J.; Kitani, A.; Watanabe, T. Signaling pathways and molecular interactions of NOD-1 and NOD-2. Nat. Rev. Immunol. 2006, 6, 9-20. [CrossRef] [PubMed]

23. Gasché, C.; Nemeth, M.; Grundtner, P.; Willheim-Polli, C.; Ferenci, P.; Schwarzenbacher, R. Evolution of Crohn's disease-associated Nod2 mutations. Immunogenetics 2008, 60, 115-120. [CrossRef] [PubMed]

24. Henckaerts, L.; Vermeire, S. NOD/2 CARD 15 disease associations other than CD. Inflamm. Bowel Dis. 2007, 13, 235-241. [CrossRef] [PubMed]

25. Cohavy, O.; Bruckner, D.; Gordon, L.K.; Misra, R.; Wei, B.; Eggena, M.E.; Targan, S.R.; Braun, J. Colonic bacteria express an Ulcerative Colitis p-ANCA related protein epitope. Infect. Immun. 2000, 68, 1542-1548. [CrossRef] [PubMed]

26. Kuna, A.T. Serological markers of IBD. Biochem. Med. (Zagreb) 2013, 23, 28-42. [CrossRef] [PubMed]

27. Niess, J.H.; Brand, S.; Gu, X.; Landsman, L.; Jung, S.; McCormick, B.A.; Vyas, J.M.; Boes, M.; Ploegh, H.L.; Fox, J.G.; et al. CX3CR1-mediated dendritic cell access to the intestinal lumen and bacterial clearance. Science 2005, 307, 254-258. [CrossRef] [PubMed]

28. Actis, G.C. The Gut Microbiome. Inflamm. Allergy Drug Targets 2014, 13, 217-223. [CrossRef] [PubMed]

29. Strober, W.; James, S.P. The mucosal immune system. In Basic Human Immunology; Stites, D.P., Terr, A., Norwalk, C.T., Eds.; Appleton \& Lange: New York, NY, USA, 1991; pp. 175-186. 
30. Fasano, A. Zonulin and its regulation of intestinal barrier function: The biological door to inflammation, autoimmunity, and cancer. Physiol. Rev. 2011, 91, 151-175. [CrossRef] [PubMed]

31. Müller, M.; Krammer, P.H. Integrated cell function: Apoptosis. In The liver: Biology and Pathobiology; Arias, I.M., Ed.; Lippincott Williams \& Wilkins: Philadelphia, PA, USA, 2001; pp. 187-205.

32. Doering, J.; Begue, B.; Lentze, M.J.; Rieux-Laucat, F.; Goulet, O.; Schmitz, J.; Cerf-Bensussan, N.; Ruemmele, F.M. Induction of T-lymphocyte apoptosis by sulphasalazin in patients with Crohn's Disease. Gut 2004, 53, 1632-1638. [CrossRef] [PubMed]

33. Tiede, I.; Fritz, G.; Strand, S.; Poppe, D.; Dvorsky, R.; Strand, D.; Lehr, H.A.; Wirtz, S.; Becker, C.; Atreya, R.; et al. CD-28 dependent Rac-1 activation is the molecular target of azathioprine in primary human CD4+ T lymphocytes. J. Clin. Investig. 2003, 111, 1133-1145. [CrossRef] [PubMed]

34. Levin, A.D.; Wildenberg, M.E.; van den Brink, G.R. Mechanism of action of anti-TNF therapy in IBD. J. Crohn's Colitis 2016, 10, 989-997. [CrossRef] [PubMed]

35. Lan, R.Y.; Mackay, I.R.; Gershwin, M.E. Regulatory T-cells in the prevention of mucosal inflammatory disorders: Patrolling the border. J. Autoimmun. 2007, 29, 272-280. [CrossRef] [PubMed]

36. Tan, Q.K.G.; Louie, R.J.; Sleasman, J.W. IPEX Syndrome. In GeneReviews ${ }^{\circledR}$; Adam, M.P., Ardinger, H.H., Pagon, R.A., Wallace, S.E., Bean, L.J.H., Stephens, K., Amemiya, A., Eds.; University of Washington: Seattle, WA, USA, 2004.

37. Marks, D.J.; Miyagi, K.; Rahman, F.Z.; Novelli, M.; Bloom, S.L.; Segal, A.W. Inflammatory bowel disease in CGD reproduces the clinicopathological features of Crohn's disease. Am. J. Gastroenterol. 2009, 104, 117-124. [CrossRef] [PubMed]

38. Uhlig, H.H.; Schwerd, T. From Genes to Mechanisms: The Expanding Spectrum of Monogenic Disorders Associated with Inflammatory Bowel Disease. Inflamm. Bowel Dis. 2016, 22, 202-212. [CrossRef] [PubMed]

39. Actis, G.C.; Pellicano, R. The pathologic galaxy modulating the genotype and phenotype of inflammatory bowel disease: Comorbidity, contiguity, and genetic and epigenetic factors. Min. Med. 2016, 107, 401-412.

40. Blank, M.; Shiloh, Y. Programs for cell death: Apoptosis is only one way to go. Cell Cycle 2007, 6, 6-95. [CrossRef] [PubMed]

41. Obexer, P.; Ausserlechner, M.J. X-linked inhibitor of apoptosis protein-A critical death resistance regulator and therapeutic target for personalized cancer therapy. Front. Oncol. 2014, 4, 197. [CrossRef] [PubMed]

42. Latour, S.; Aguilar, C. XIAP deficiency syndrome in humans. Semin. Cell Dev. Biol. 2015, 39, 115-123. [CrossRef] [PubMed]

43. Worthey, E.A.; Mayer, A.N.; Syverson, G.D.; Helbling, D.; Bonacci, B.B.; Decker, B.; Serpe, J.M.; Dasu, T.; Tschannen, M.R.; Veith, R.L.; et al. Making a definitive diagnosis: Successful clinical application of whole exome sequencing in a child with intractable inflammatory bowel disease. Genet. Med. 2011, 13, 255-262. [CrossRef] [PubMed]

44. Coelho, R.; Peixoto, A.; Amil-Dias, J.; Trindade, E.; Campos, M.; Magina, S.; Charbit-Henrion, F.; Lenoir, C.; Latour, S.; Magro, F.; et al. Refractory monogenic Crohn's disease due to X-linked inhibitor of apoptosis deficiency. Int. J. Colorectal Dis. 2016, 31, 1235-1236. [CrossRef] [PubMed]

45. Darnell, J.E., Jr.; Kerr, I.M.; Stark, G.R. Jak-STAT pathways and transcriptional activation in response to IFNs and other extracellular signaling proteins. Science 1994, 264, 1415-1421. [CrossRef] [PubMed]

46. Fu, X.Y. STAT3 in immune responses and inflammatory bowel diseases. Cell Res. 2006, 16, 214-219. [CrossRef] [PubMed]

47. Glocker, E.O.; Kotlarz, D.; Boztug, K.; Gertz, E.M.; Schäffer, A.A.; Noyan, F.; Perro, M.; Diestelhorst, J.; Allroth, A.; Murugan, D.; et al. Inflammatory bowel disease and mutations affecting the interleukin-10 receptor. N. Engl. J. Med. 2009, 361, 2033-2045. [CrossRef] [PubMed]

48. Chalaris, A.; Adam, N.; Sina, C.; Rosenstiel, P.; Lehmann-Koch, J.; Schirmacher, P.; Hartmann, D.; Cichy, J.; Gavrilova, O.; Schreiber, S.; et al. Critical role of the disintegrin metalloprotease ADAM17 for intestinal inflammation and regeneration in mice. J. Exp. Med. 2010, 207, 1617-1624. [CrossRef] [PubMed]

49. Blaydon, D.C.; Biancheri, P.; Di, W.L.; Plagnol, V.; Cabral, R.M.; Brooke, M.A.; van Heel, D.A.; Ruschendorf, F.; Toynbee, M.; Walne, A.; et al. Inflammatory skin and bowel disease linked to ADAM17 deletion. N. Engl. J. Med. 2011, 365, 1502-1508. [CrossRef] [PubMed]

50. Fagoonee, S.; Pellicano, R.; Actis, G.C. ADAM17 and gastrointestinal tract diseases: Clinical aspects with translational messages. Minerva Biotechnol. 2018, 30, 22-28. 
51. Abraham, C.; Cho, J. Interleukin-23/Th17 pathways and inflammatory bowel disease. Inflamm. Bowel Dis. 2009, 15, 1090-1100. [CrossRef] [PubMed]

52. Wang, J.; Bhatia, A.; Krugliak Cleveland, N.; Gupta, N.; Dalal, S.; Rubin, D.T.; Sakuraba, A. Rapid Onset of Inflammatory Bowel Disease after Receiving Secukinumab Infusion. ACG Case Rep. J. 2018, 5, e56. [CrossRef] [PubMed]

53. Rozin, A.P.; Hasin, T.; Toledano, K.; Guralnik, L.; Balbir-Gurman, A. Seronegative polyarthritis as severe systemic disease. Neth. J. Med. 2010, 68, 236-241. [PubMed]

54. Tilg, H.; Moschen, A.R. Food, immunity, and the microbiome. Gastroenterology 2015, 148, 1107-1119. [CrossRef] [PubMed]

55. Martinez, I.; Stegen, J.C.; Maldonado-Gómez, M.X.; Eren, A.M.; Siba, P.M.; Greenhill, A.R.; Walter, J. The gut microbiota of rural papua new guineans: Composition, diversity patterns, and ecological processes. Cell Rep. 2015, 11, 527-538. [CrossRef] [PubMed]

56. Hart, A.R.; Luben, R.; Olsen, A.; Tjonneland, A.; Linseisen, J.; Nagel, G.; Berglund, G.; Lindgren, S.; Grip, O.; Key, T.; et al. Diet in the aetiology of ulcerative colitis: A European prospective cohort study. Digestion 2008, 77, 57-64. [CrossRef] [PubMed]

57. Sigall-Boneh, R.; Levine, A.; Lomer, M.; Wierdsma, N.; Allan, P.; Fiorino, G.; Gatti, S.; Jonkers, D.; Kierkus, J.; Katsanos, K.H.; et al. Research Gaps in Diet and Nutrition in Inflammatory Bowel Disease. A Topical Review by D-ECCO Working Group [Dietitians of ECCO]. J. Crohns Colitis 2017, 11, 1407-1419. [CrossRef] [PubMed]

58. Gerasimidis, K.; McGrogan, P.; Edwards, C.A. The aetiology and impact of malnutrition in paediatric inflammatory bowel disease. J. Hum. Nutr. Diet. 2011, 24, 313-326. [CrossRef] [PubMed]

59. Brasil Lopes, M.; Rocha, R.; Castro Lyra, A.; Rosa Oliveira, V.; Gomes Coqueiro, F.; Silveira Almeida, N.; Santos Valois, S.; Oliveira Santana, G. Restriction of dairy products; A reality in inflammatory bowel disease patients. Nutr. Hosp. 2014, 29, 575-581. [PubMed]

60. Carolan, E.; Hogan, A.E.; Corrigan, M.; Gaotswe, G.; O'Connell, J.; Foley, N.; O’Neill, L.A.; Cody, D.; O'Shea, D. The impact of childhood obesity on inflammation, innate immune cell frequency, and metabolic microRNA expression. J. Clin. Endocrinol. Metab. 2014, 99, E474-E478. [CrossRef] [PubMed]

61. Ozawa, M.; Shipley, M.; Kivimaki, M.; Singh-Manoux, A.; Brunner, E.J. Dietary pattern, inflammation and cognitive decline: The Whitehall II prospective cohort study. Clin. Nutr. 2017, 36, 506-512. [CrossRef] [PubMed]

62. Dror, E.; Dalmas, E.; Meier, D.T.; Wueest, S.; Thévenet, J.; Thienel, C.; Timper, K.; Nordmann, T.M.; Traub, S.; Schulze, F.; et al. Postprandial macrophage-derived IL-1 $\beta$ stimulates insulin, and both synergistically promote glucose disposal and inflammation. Nat. Immunol. 2017, 18, 283-292. [CrossRef] [PubMed]

63. Maciver, N.J.; Jacobs, S.R.; Wieman, H.L.; Wofford, J.A.; Coloff, J.L.; Rathmell, J.C. Glucose metabolism in lymphocytes is a regulated process with significant effects on immune cell function and survival. J. Leukoc. Biol. 2008, 84, 949-957. [CrossRef] [PubMed]

64. Fedrigo, O.; Pfefferle, A.D.; Babbitt, C.C.; Haygood, R.; Wall, C.E.; Wray, G.A. A potential role for glucose transporters in the evolution of human brain size. Brain Behav. Evol. 2011, 78, 315-326. [CrossRef] [PubMed]

65. Ananthakrishnan, A.N.; Higuchi, L.M.; Huang, E.S.; Khalili, H.; Richter, J.M.; Fuchs, C.S.; Chan, A.T. Aspirin, nonsteroidal anti-inflammatory drug use, and risk for Crohn disease and ulcerative colitis: A cohort study. Ann. Int. Med. 2012, 156, 350-359. [CrossRef] [PubMed]

66. Toussirot, E.; Houvenagel, É.; Goëb, V.; Fouache, D.; Martin, A.; Le Dantec, P.; Dernis, E.; Wendling, D.; Ansemant, T.; Berthelot, J.M.; et al. Development of inflammatory bowel disease during anti-TNF- $\alpha$ therapy for inflammatory rheumatic disease: A nationwide series. Jt. Bone Spine 2012, 79, 457-463. [CrossRef] [PubMed]

67. Dubeau, M.F.; Iacucci, M.; Beck, P.L.; Moran, G.W.; Kaplan, G.G.; Ghosh, S.; Panaccione, R. Drug-induced inflammatory bowel disease and IBD-like conditions. Inflamm. Bowel Dis. 2013, 19, 445-456. [CrossRef] [PubMed]

68. Kelsen, J.; Agnholt, J.; Dige, A.; Christensen, L.A.; Dahlerup, J.F. Discrete changes in circulating regulatory T cells during infliximab treatment of Crohn's disease. Autoimmunity 2010, 43, 325-333. [CrossRef]

69. Actis, G.C.; Lagget, M.; Pellicano, R.; Rosina, F. Pancolitis during etanercept treatment of rheumatoid arthritis relapsing on the administration of further two TNF-alpha inhibitors. Int. J. Colorectal Dis. 2012, 27, 547-548. [CrossRef] [PubMed] 
70. Parkes, G.C.; Whelan, K.; Lindsay, J.O. Smoking in inflammatory bowel disease: Impact on disease course and insights into the aetiology of its effect. J. Crohn's Colitis 2014, 8, 717-725. [CrossRef] [PubMed]

71. Meregnani, J.; Clarençon, D.; Vivier, M.; Peinnequin, A.; Mouret, C.; Sinniger, V.; Picq, C.; Job, A.; Canini, F.; Jacquier-Sarlin, M.; et al. Anti-inflammatory effect of vagus nerve stimulation in a rat model of inflammatory bowel disease. Auton. Neurosci. 2011, 160, 82-89. [CrossRef] [PubMed]

72. Cuoco, J.A.; Fennie, C.N.; Cheriyan, G.K. The Cholinergic Anti-Inflammatory Pathway: A Novel Paradigm for Translational Research in Neuroimmunology. J. Neurol. Neurosci. 2016, 7, 1-7. [CrossRef]

73. Bonaz, B.; Sinniger, V.; Hoffmann, D.; Clarençon, D.; Mathieu, N.; Dantzer, C.; Vercueil, L.; Picq, C.; Trocmé, C.; Faure, P.; et al. Chronic vagus nerve stimulation in Crohn's disease: A 6-month follow-up pilot study. Neurogastroenterol. Motil. 2016, 28, 948-953. [CrossRef] [PubMed]

74. Kushwah, R.; Hu, J. Dendritic cell apoptosis. J. Immunol. 2010, 185, 795-802. [CrossRef] [PubMed]

75. Chen, M.; Wang, Y.H.; Wang, Y.; Huang, L.; Sandoval, H.; Liu, Y.J.; Wang, J. Dendritic cell apoptosis in the maintenance of immune tolerance. Science 2006, 311, 1160-1164. [CrossRef] [PubMed]

76. Roda, G.; Sartini, A.; Zambon, E.; Calafiore, A.; Marocchi, M.; Caponi, A.; Belluzzi, A.; Roda, E. Intestinal epithelial cells in inflammatory bowel diseases. World J. Gastroenterol. 2010, 16, 4264-4271. [CrossRef] [PubMed]

77. Molodecky, N.A.; Soon, I.S.; Rabi, D.M.; Ghali, W.A.; Ferris, M.; Chernoff, G.; Benchimol, E.I.; Panaccione, R.; Ghosh, S.; Barkema, H.W.; et al. Increasing Incidence and Prevalence of the IBDs with time, based on systematic review. Gastroenterology 2012, 142, 46-54.e42. [CrossRef] [PubMed]

78. Yang, Y.; Owyang, C.; Wu, G.D. East meets the West: The Increasing Incidence of Inflammatory Bowel Disease in Asia as a Paradigm for Environmental Effects on the Pathogenesis of Immune-Mediated Disease. Gastroenterology 2016, 151, e1-e5. [CrossRef] [PubMed]

79. $\mathrm{Ng}, \mathrm{S} . \mathrm{C}$. Emerging leadership lecture: Inflammatory bowel disease in Asia: Emergence of a "Western" disease. J. Gastroenterol. Hepatol. 2015, 30, 440-445. [CrossRef] [PubMed]

80. Malekzadeh, M.M.; Vahedi, H.; Gohari, K.; Mehdipour, P.; Sepanlou, S.G.; Ebrahimi Daryani, N.; Zali, M.R.; Mansour-Ghanaei, F.; Safaripour, A.; Aghazadeh, R.; et al. Emerging Epidemic of Inflammatory Bowel Disease in a Middle Income Country: A Nation-wide Study from Iran. Arch. Iran. Med. 2016, 19, 2-15. [PubMed]

81. Lopez, R.N.; Appleton, L.; Gearry, R.B.; Day, A.S. Rising Incidence of Paediatric Inflammatory Bowel Disease in Canterbury, New Zealand, 1996-2015. J. Pediatr. Gastroenterol. Nutr. 2018, 66, e45. [CrossRef] [PubMed]

82. Benchimol, E.; Mack, D.R.; Guttmann, A.; Nguyen, G.C.; To, T.; Mojaverian, N.; Quach, P.; Manuel, D.G. Inflammatory bowel disease in immigrants to Canada and their children: A population-based cohort study. Am. J. Gastroenterol. 2015, 110, 553-563. [CrossRef] [PubMed]

83. Damas, O.M.; Avalos, D.J.; Palacio, A.M.; Gomez, L.; Quintero, M.A.; Deshpande, A.R.; Sussman, D.A.; McCauley, J.L.; Lopez, J.; Schwartz, S.J.; et al. Inflammatory bowel disease is presenting sooner after immigration in more recent US immigrants from Cuba. Aliment. Pharmacol. Ther. 2017, 46, 303-309. [CrossRef] [PubMed]

84. Actis, G.C.; Pellicano, R. Letter: Cuban immigrants to the US developing IBD have a progressive shortening of the lag between time of arrival and disease onset. Aliment. Pharmacol. Ther. 2017, 46, 768. [CrossRef] [PubMed]

85. Isaksson, C. Urbanization, oxidative stress and inflammation: A question of evolving, acclimatizing or coping with urban environmental stress. Funct. Ecol. 2015, 29, 913-923. [CrossRef]

86. Aller, M.A.; Arias, N.; Fuentes-Julian, S.; Blazquez-Martinez, A.; Argudo, S.; Miguel, M.P.; Arias, J.L.; Arias, J. Coupling inflammation with evo-devo. Med. Hypotheses 2012, 78, 721-731. [CrossRef] [PubMed]

87. Actis, G.C. Gastroenterology: 2018 Forecast. J. Gastroenterol. Forecast. 2018, 1, 1007.

88. Koivula, M.J.; Eeva, T. Metal-related oxidative stress in birds. Environ. Pollut. 2010, 158, 2359-2370. [CrossRef] [PubMed]

89. LaDeau, S.L.; Allan, B.F.; Leisnham, P.T.; Levy, M.Z. The ecological foundations of transmission potential and vector-borne disease in urban landscapes. Funct. Ecol. 2015, 29, 889-901. [CrossRef] [PubMed]

90. Kosek, M.; Bern, C.; Guerrant, R.L. The global burden of diarrhoeal disease, as estimated from studies published between 1992 and 2000. Bull. World Health Organ. 2003, 81, 197-204. [PubMed]

91. Ribaldone, D.G.; Pellicano, R.; Actis, G.C. Inflammation: A highly conserved, Janus-like phenomenon-A gastroenterologist' perspective. J. Mol. Med. 2018. [CrossRef] [PubMed] 
92. Oda, H.; Wakabayashi, H.; Yamauchi, K.; Abe, F. Lactoferrin and bifidobacteria. Biometals 2014, $27,915-922$. [CrossRef] [PubMed]

93. LeGrand, D. Overview of Lactoferrin as a Natural Immune Modulator. J. Pediatr. 2016, 173, S10-S15. [CrossRef] [PubMed]

94. Zuo, T.; Kamm, M.A.; Colombel, J.F.; Ng, S.C. Urbanization and the gut microbiota in health and inflammatory bowel disease. Nat. Rev. Gastroenterol. Hepatol. 2018, 15, 440-452. [CrossRef] [PubMed]

95. Ng, S.C.; Tang, W.; Ching, J.Y.; Wong, M.; Chow, C.M.; Hui, A.J.; Wong, T.C.; Leung, V.K.; Tsang, S.W.; $\mathrm{Yu}, \mathrm{H} . \mathrm{H}$.; et al. Incidence and phenotype of inflammatory bowel disease based on results from the Asia-pacific Crohn's and colitis epidemiology study. Gastroenterology 2013, 145, 158-165.e2. [CrossRef] [PubMed]

96. Soon, S.; Molodecky, N.A.; Rabi, D.M.; Ghali, W.A.; Barkema, H.W.; Kaplan, G.G. The relationship between urban environment and the inflammatory bowel diseases: A systematic review and meta-analysis. BMC Gastroenterol. 2012, 12, 51. [CrossRef] [PubMed]

97. De Filippo, C.; Cavalieri, D.; Di Paola, M.; Ramazzotti, M.; Poullet, J.B.; Massart, S.; Collini, S.; Pieraccini, G.; Lionetti, P. Impact of diet in shaping gut microbiota revealed by a comparative study in children from Europe and rural Africa. Proc. Natl. Acad. Sci. USA 2010, 107, 14691-14696. [CrossRef] [PubMed]

98. Kostic, A.D.; Xavier, R.J.; Gevers, D. The microbiome in inflammatory bowel disease: Current status and the future ahead. Gastroenterology 2014, 146, 1489-1499. [CrossRef] [PubMed]

99. Ottman, N.; Smidt, H.; de Vos, W.M.; Belzer, C. The function of our microbiota: Who is out there and what do they do? Front. Cell. Infect. Microbiol. 2012, 2, 104. [CrossRef] [PubMed]

100. Moustafa, A.; Li, W.; Anderson, E.L.; Wong, E.H.M.; Dulai, P.S.; Sandborn, W.J.; Biggs, W.; Yooseph, S.; Jones, M.B.; Venter, J.C.; et al. Genetic risk, dysbiosis, and treatment stratification using host genome and gut microbiome in inflammatory bowel disease. Clin. Transl. Gastroenterol. 2018, 9, e132. [CrossRef] [PubMed]

101. Zhou, Y.; Xu, Z.Z.; He, Y.; Yang, Y.; Liu, L.; Lin, Q.; Nie, Y.; Li, M.; Zhi, F.; Liu, S.; et al. Gut Microbiota Offers Universal Biomarkers across Ethnicity in Inflammatory Bowel Disease Diagnosis and Infliximab Response Prediction. mSystems 2018, 3, e00188-17. [CrossRef] [PubMed]

102. Li, Y.; Tian, Y.; Zhu, W.; Gong, J.; Gu, L.; Zhang, W.; Guo, Z.; Li, N.; Li, J. Cesarean delivery and risk of inflammatory bowel disease: A systematic review and meta-analysis. Scand. J. Gastroenterol. 2014, 49, 834-844. [CrossRef] [PubMed]

103. Browne, H.P.; Neville, B.A.; Forster, S.C.; Lawley, T.D. Transmission of the gut microbiota: Spreading of health. Nat. Rev. Microbiol. 2017, 15, 531-543. [CrossRef] [PubMed]

104. Ribaldone, D.G.; Fagoonee, S.; Colombini, J.; Saracco, G.; Astegiano, M.; Pellicano, R. Helicobacter Pylori infection and asthma: Is there a direct or an inverse association? A meta-analysis. World J. Meta-Anal. 2016, 4, 63-68. [CrossRef]

105. Alonso-López, D.; Gutierrez, M.A.; Lopes, K.P.; Prieto, C.; Santamaría, R.; De Las Rivas, J. APID interactomes: Providing proteome-based interactomes with controlled quality for multiple species and derived networks. Nucleic Acid Res. 2016, 44, W529-W535. [CrossRef] [PubMed]

106. Fiocchi, C. Inflammatory Bowel Disease: Complexity and Variability Need Integration. Front. Med. (Lausanne) 2018, 5, 75. [CrossRef] [PubMed]

107. De Souza, H.S.P.; Fiocchi, C.; Iliopoulos, D. The IBD interactome: An integrated view of aetiology, pathogenesis and therapy. Nat. Rev. Gastroenterol. Hepatol. 2017, 14, 739-749. [CrossRef] [PubMed]

(C) 2018 by the authors. Licensee MDPI, Basel, Switzerland. This article is an open access article distributed under the terms and conditions of the Creative Commons Attribution (CC BY) license (http:/ / creativecommons.org/licenses/by/4.0/). 